\title{
Internacionalização impacta os indicadores de curto prazo? um estudo sobre empresas brasileiras
}

\section{Luciano Pinheiro de Sá, Josir Simeone Gomes, Jadilson Borges Moreira}

\author{
Departamento de Finanças e Controladoria \\ Universidade Federal de Juiz de Fora \\ Programa de Mestrado e Doutorado en Administraçao \\ Universidade do Grande Rio \\ Departamento de Ciências Administrativas e Sociais \\ Universidade Federal Rural do Rio de Janeiro
}

A proposta deste artigo investiga a relaçáo existente entre o grau de internacionalizaçáo de empresas brasileiras e os indicadores de performance financeira. Quanto ao método, o estudo utilizou bases quantitativas com hipóteses desenvolvidas, testadas e analisadas em dois modelos de regressão. A amostra final resulta em dados de 72 empresas brasileiras abertas. A origem é de duas fontes secundárias distintas. $\mathrm{O}$ indicador de internacionalização, a partir do Ranking das multinacionais brasileiras divulgados anualmente pela Fundação Dom Cabral (Brasil). As informaçóes financeiras têm origem na base de dados Economatica@. O período de análise compreende o intervalo de 2011 a 2015. O primeiro modelo de regressão subsidia as análises a partir das variaçóes dos indicadores entre dois exercícios sociais. O segundo modelo relaciona os indicadores dentro do mesmo exercício social. Os resultados indicaram a não associação entre grau de internacionalização e os indicadores de performance financeira de curto prazo em empresas brasileiras que têm seu nível de internacionalização divulgado anualmente por metodologia específica da Fundação Dom Cabral, provendo contribuiçôes para a sociedade que necessita de informaçóes desta qualidade. A principal restrição do trabalho foi o número de empresas da amostra.

Palavras-chave: performance financeira, internacionalização, contabilidade gerencial.

\section{Internationalization Impact the Short-Term Indicators? A Study on Brazilian Companies}

The proposal of this article investigates the relationship between the degree of internationalization of Brazilian companies and the financial performance indicators. Regarding the method, the study used quantitative bases with hypotheses developed, tested and analyzed in two regression models. The final sample results in data from 72 Brazilian companies. The source is from two separate secondary sources. The index of internationalization, based on the Ranking of Brazilian multinationals published annually by Fundação Dom Cabral (Brazil). The financial information comes from the Economatica (C) database. The period of analysis comprises the interval from 2011 to 2015. The first regression model subsidizes the analyzes from the variations of the indicators between two fiscal years. The second model relates the indicators within the same fiscal year. The results indicated the lack of association between the degree of internationalization and the indicators of short-term financial performance in Brazilian companies that have their level of internationalization published annually by specific methodology of the Dom Cabral Foundation, providing contributions to the society that needs this information roll. The main restriction of the work was the number of companies in the sample.

Keywords: Financial Performance, Internationalization, Management Accounting. 


\section{Internacionalización impacta los indicadores de corto plazo? un estudio sobre empresas brasileńas}

La propuesta de este artículo investiga la relación existente entre el grado de internacionalización de empresas brasileñas y los indicadores de desempeño financiero. En cuanto al método, el estudio utilizó bases cuantitativas con hipótesis desarrolladas, probadas y analizadas en dos modelos de regresión. La muestra final resulta en datos de 72 empresas brasileńas abiertas. El origen es de dos fuentes secundarias distintas. El indicador de internacionalización, a partir del Ranking de las multinacionales brasileñas divulgadas anualmente por la Fundación Dom Cabral (Brasil). La información financiera procede de la base de datos Económica @. El período de análisis comprende el intervalo de 2011 a 2015. El primer modelo de regresión subsidia los análisis a partir de las variaciones de los indicadores entre dos ejercicios sociales. El segundo modelo relaciona los indicadores dentro del mismo ejercicio social. Los resultados indicaron la no asociación entre grado de internacionalización y los indicadores de desempeńo financiero a corto plazo en empresas brasileñas que tienen su nivel de internacionalización divulgado anualmente por metodología específica de la Fundación Dom Cabral, aportando contribuciones a la sociedad que necesita ese rol de informaciones. La principal restricción del trabajo fue el número de empresas de la muestra.

Palabras clave: rendimiento financiero, internacionalización, contabilidad gerencial.

\section{Introdução}

As aberturas comerciais empreendidas nas principais economias mundiais possibilitam que gestores incluam no planejamento estratégico a decisão de expansão para atuação para além da economia de origem do capital. Possibilidades de vantagens estáo conectadas a maiores exposiçóes de riscos organizacionais. Entre as vantagens, cita-se um maior mercado consumidor disposto a consumir produtos e serviços em quantidades que superam o mercado doméstico, ou até mesmo dispostos a consumir outros tipos e qualidades de produtos em que o mercado doméstico não tem interesse.

Por outro lado, a mesma abertura comercial pode aumentar a concorrência doméstica, exigindo que as empresas busquem redução de custos, maior modernização para a manutenção da competitividade (Marostica, Borgert, Souza, \& Petri, 2017). Ainda sobre esses riscos adicionais, a atuaçáo em mercado distintos pode incorrer em situaçóes que não permitam que sejam atingidos os melhores níveis de performance operacional ou financeira. Tal condição pode indicar a perda de valor empresarial com consequências para diversos stakeholders envolvidos.

Os diferenciais de performance podem estar expressos nos mais diversos indicadores. Como a contabilidade é uma ciência social aplicada, esforça-se para acompanhar a crescente complexidade das organizaçóes com seus diversos atores envolvidos, dentre eles investidores, credores, governo e representação de funcionários. Quanto à performance financeira, surgem como relevantes investigações que mensurem, por meio de indicadores financeiros, as atividades de empresas internacionalizadas e suas conexôes com esses indicadores.

A presente pesquisa tem como foco a investigação no contexto de empresas abertas brasileiras a relação entre o grau de internacionalização e os indicadores financeiros de curto prazo. A exposição em mercados distintos dos de origem traz maiores exposiçóes a riscos para as empresas. A investigação que envolve as variaçóes nos indicadores financeiros de curto prazo pode prover elementos adicionais de informaçóes para a tomada de decisão dos diversos stakeholders. 
Durante a construção deste trabalho, observou-se lacunas em pesquisas positivistas que pudessem tratar as modificaçóes em indicadores financeiros de curto prazo quando empresas brasileiras desenvolvem seus negócios em outros países. A importância da investigação reside no fato de que as empresas brasileiras buscam aumentar atividades em mercados distintos do interno. Como provedores de fundos, investidores e a sociedade de forma geral estão conectadas às empresas abertas, reside um espaço para uma mais ampla investigação dos efeitos financeiros que os movimentos de internacionalização podem ou não produzir.

Como questão orientadora, a presente pesquisa busca investigar: Qual a relaçáo entre o grau de internacionalização e indicadores financeiros de curto prazo?

Buscando uma abrangência maior, a opção foi em investigar as empresas abertas de todos os setores brasileiros com dados públicos, restrita às empresas que têm o indicador de internacionalização divulgado pela Fundação Dom Cabral. Como marco temporal, a investigação se estrutura no período entre 2011 e 2015. Também optou por desenvolver hipóteses que foram testadas. Utilizou-se como proxy do grau de internacionalização um indicador mensurado e divulgado anualmente pela Fundação Dom Cabral. A partir de dois modelos de regressão, foi possível diagnosticar se existem e quais os níveis de algumas associações.

A partir de um breve referencial teórico, estruturaram-se quatro hipóteses em que, das que foram empreendidas no trabalho, nenhuma pode ser confirmada. Então, o principal achado nesta pesquisa foi que, em um contexto brasileiro, no período de 2011 e 2015, os indicadores financeiros de Liquidez Geral, Margem Líquida, Variação do Lucro por Ação e Estrutura de Capital não estáo positivamente associados ao grau de internacionalização. $\mathrm{O}$ único encontro a um nível estabelecido de significância de 5\% foi a associação negativa entre a Margem Líquida e o grau de internacionalização, no mesmo exercício social.

Os achados corvejem para a possibilidade de que os efeitos financeiros da internacionalização de empresas brasileiras levam mais tempo para ocorrer. Neste ponto reside espaço para futuras pesquisas que possam ampliar o tempo de investigação.

Após essa breve introdução, o trabalho apresenta mais seis seções. A seção três trata da revisão da literatura, a seção quatro cuida do percurso metodológico, incluindo as hipóteses. Restam para a as seçóes cinco e seis as análises e discussóes dos resultados. As considerações finais são tratadas na seção sete, restando a última para as referências utilizadas.

Este artigo foi apresentado no XI Congreso Iberoamericano de Contabilidad de Gestión e I Congreso Iberoamericano de Contabilidad y Finanzas, em junho de 2017, na cidade de Lima (Peru) com o título "Impactos nos indicadores financeiros face às variaçóes no grau de internacionalização de empresas brasileiras".

\section{Revisão da literatura}

\subsection{Avaliação de performance de negócios}

Até recentemente, a literatura de economia internacional e a literatura de finanças corporativas evoluíram separadamente. A investigação sobre o comércio internacional centrou-se no papel das economias de escala e nas diferenças entre países, em termos de produtividade e dotação de fatores na previsão dos ganhos do comércio e do padrão dos fluxos comerciais agregados de acordo com a vantagem comparativa, conforme Foley e Manova (2015).

Em um contexto de fluxo de informaçóes tão volumoso, a análise de performance de uma organização 
requer atenção de todos os seus usuários. Por essa ótica, os relatórios financeiros são instrumentos utilizados pelos interessados em ter uma percepção da situação de uma corporação, com esforços para prever minimamente o seu comportamento no futuro. Para que a análise e a discussão da gestão sobre resultado, desempenho e comparabilidade para a tomada de decisão sejam processadas, toda uma estrutura padronizada de orientaçóes é requerida. Com base na divulgação dessas informaçóes, profissionais de áreas tais como economia, contabilidade e finanças analisam o conteúdo dessas fontes, alimentando seus clientes de relatórios e informaçóes (Penman, 2013). Uma análise global da complexidade e da sofisticação do fluxo de capitais entre economias, suas características próprias, condiçôes regulatórias e participação estatal reforça a importância de que a produção dessas informaçóes esteja alinhada a parâmetros razoavelmente próximos.

Embora as prescriçóes para melhorar e gerenciar o desempenho organizacional estejam amplamente disponíveis, a comunidade acadêmica, conforme Venkatraman e Ramanujam (1986) tem se preocupado com discussóes e debates sobre questóes de terminologia, níveis de análise e bases de análise para o desempenho.

\subsection{Internacionalizaçáo}

O procedimento de graduação nos processos de internacionalização de empresas suecas foi apresentado por Johanson e Wiedersheim-Paul em 1975. Esses autores, conforme Teixeira e Flores (2014), identificaram que as características essenciais da internacionalização dessas empresas, objeto do estudo, eram os parcos investimentos e o aumento gradual de suas relaçóes com o exterior.

Trazendo uma abordagem para os aspectos do mercado interno, Hilal e Hemais afirmam que "Quando o mercado doméstico está saturado e, consequentemente, o número de oportunidades lucrativas diminui até o ponto de impedir a ampliação da firma, deve-se buscar novos locais para se expandir" (2003, p. 111).

Como abordado por Teixeira e Flores (2014), Carneiro e Dib propóem uma divisão de expectativas das teorias de internacionalização, como abordagens baseadas em critérios econômicos e abordagens sustentadas na evolução comportamental. A Tabela 1 expóe esses elementos:

\section{Tabela 1. Teorias de Internacionalizaçáo}

\begin{tabular}{|l|l|}
\hline $\begin{array}{c}\text { Abordagem baseada em } \\
\text { critérios econômicos }\end{array}$ & $\begin{array}{c}\text { Abordagem calcadas na evoluçáo } \\
\text { comportamental }\end{array}$ \\
\hline $\begin{array}{l}\text { Teorias orientadas pra } \\
\text { decisóes pseudo racionais. } \\
\begin{array}{l}\text { Decisóes estruturadas de } \\
\text { uma forma que privilegie a } \\
\text { maximizaçáo dos retornos } \\
\text { alcançados }\end{array}\end{array}$ & $\begin{array}{l}\text { Processos que dependem das ati- } \\
\text { tudes, percepçóes e comporta- } \\
\text { mentos dos tomadores de decisão, } \\
\text { que estariam orientados para } \\
\text { reduzir os riscos das decisóes de } \\
\text { onde e como expandir. }\end{array}$ \\
\hline
\end{tabular}

Fonte: Teixeira, Flores, 2014.

A respeito desses estágios no processo de internacionalização,

A sequência de modos de operação se inicia com um envolvimento leve, geralmente representado por exportação direta, quando se tem a oportunidade de adquirir conhecimentos sobre o novo mercado. O envolvimento se aprofunda a partir do aumento desses conhecimentos e da melhoria dos canais de informação, podendo a firma chegar a um alto envolvimento, representado pelo estabelecimento de subsidiárias no país estrangeiro. A seqüência na seleção de mercados abrange a entrada sucessiva em mercados cada vez mais psiquicamente distantes, à medida que a firma ganha experiência de operaçóes estrangeiras. (Hilal; Hemais, 2003, p. 111)

À medida que a atuação geográfica operacional de uma empresa se amplia, sua complexidade administrativa também cresce, exigindo a adoção de sistemas de controle novos e mais sofisticados (Martinewski; Gomes, 2001). Assim, é importante a atenção dada à atmosfera 
institucional de cada país em que uma organização desenvolve suas atividades, incluindo o seu sistema jurídico, regulamentação, acesso a soluções legais e execução obrigatória de contratos. A estrutura sindical e as relaçóes trabalhistas também devem ser examinadas. A organização do sistema financeiro e o tamanho do mercado financeiro são também aspectos importantes para verificar a possibilidade e as condiçóes para obtenção de recursos, além as normativas contábeis (Merchant, 1998; Martinewski; Gomes, 2001).

O processo torna-se mais crítico quando empresas internacionalizadas realizam investimentos diretos em outros países, devido à necessidade de expansão do escopo do controle de recursos financeiros e humanos alocados no exterior. Um sistema de controle único não é compatível com as características culturais de diferentes países, exigindo o uso de mecanismos de controle adicionais para lidar com o novo escopo de negócios. Tal premissa baseia-se no pensamento de Dyment (1987), que propóe que a administração de uma empresa globalizada deve ser significativamente diferente de uma empresa doméstica ou de uma multinacional, e sua estrutura de controle de gestão deve ser adequada a uma estratégia global.

O desempenho das exportaçóes é um complexo e multifacetado construto que demanda cuidados especiais quanto à definição e às formas de mensuração para evoluir, testar teoria e contribuir na melhora das práticas gerenciais (Carneiro et al., 2016). Na medida em que a concorrência internacional aumenta, é importante desenvolver e implementar estratégias bem-sucedidas para garantir resultados de desempenho de exportação satisfatórios (Cieslik; Kaciak; Thongpapanl, 2015). Assumindo um sistema integrado, organizaçóes mais expostas a mercados internacionais podem ter reflexos em seus indicadores econômico-financeiros.

\subsection{Outros trabalhos sobre o tema}

Pesquisadores têm dedicado esforços no estudo dos impactos da internacionalização e seu desempenho. Floriani e Fleury (2012) tiveram como objetivo a identificação entre o grau de internacionalização, o desempenho financeiro e o desenvolvimento de competências internacionais das Pequenas e Médias Empresas brasileiras. Empreenderam um estudo em survey com 114 empresas testando a hipótese de que a elevação do grau de internacionalização pudesse desenvolver competências internacionais e melhorar o desempenho financeiro. Para as autoras, os resultados indicaram que, com o aumento do grau de internacionalização, a Pequena e Média Empresa desenvolve competências internacionais e, assim, apresenta um desempenho superior.

Barcellos (2010) investigou de que maneira a internacionalização tem contribuído para o desempenho financeiro das empresas brasileiras como um todo e para o desempenho financeiro das suas operaçóes internacionais. Também por meio de uma survey com 51 empresas de capital nacional, fazendo uso de modelo de regressão simples e multivariado, segundo a autora, a pesquisa proporcionou uma reflexão sobre a relação entre o grau de internacionalização e desempenho financeiro. Os resultados indicaram que o desempenho financeiro geral das multinacionais brasileiras está associado ao grau de internacionalização.

A internacionalização de uma organização, conjuntamente com o surgimento de empresas multinacionais, não é uma exclusividade da economia contemporânea. No caso brasileiro, estes movimentos ganharam destaque a partir da década de 1990, com a abertura comercial do país. Silva e Boaventura (2011) procuraram analisar a estratégia de internacionalização de empresas brasileiras, mais especificamente de empresas de capital aberto com investimento direto no exterior 
em valores que excedessem US\$ 10 milhóes. Empreenderam um estudo quantitativo empregando o grau de internacionalização e a variação do desempenho financeiro. Os achados dos autores convergiram para a conclusão de que há uma correlação positiva fraca com indicadores financeiros de crescimento. Quanto aos elementos associados à rentabilidade, os resultados apontaram para uma relação negativa em algumas das variáveis independentes utilizadas.

\section{Aspectos metodológicos}

Em vista do perfil da investigação ser aderente à pesquisa bibliográfica, as necessidades levantadas para a busca das respostas deste trabalho são aderentes às definiçōes de pesquisa ex post facto, pois a essência proposta está embasada em eventos que já ocorreram.

O trabalho também assume um aspecto de pesquisa descritiva. Raupp e Beuren explicam que "a pesquisa descritiva tem como principal objetivo descrever características de determinada população ou fenômeno ou estabelecimento de relações entre variáveis" (Raupp; Beuren, 2014 apud Gil, 1999, p. 81).

O objeto de estudo foram as empresas que são relacionadas no Ranking das Multinacionais Brasileiras da Fundação Dom Cabral no período de 2011 a 2015. No âmbito deste trabalho, como proxy do grau de internacionalização de uma empresa foi utilizado o Índice de Internacionalização, aqui denominado de (IFDC) que é uma média aritmética das proporçóes de: Ativos no Exterior e totais; Receitas do Exterior e totais; e Número de funcionários no Exterior e Totais.

Quanto aos indicadores financeiros, os dados foram obtidos através do sistema Economática, onde estão disponíveis informaçóes financeiras de empresas listadas na BOVESPA. Procurou-se contemplar quatro principais grupos de indicadores econômico-finan- ceiros: (1) Dados por Ação; (2) Estrutura de Capital; (3) Liquidez e (4) Rentabilidade. Admitiu-se a possibilidade de as variáveis em um mesmo grupo serem fortemente correlacionadas. Essa condição faz surgir nos modelos de regressão o problema da multicolinearidade das variáveis independentes. Em sequência, foi empreendida a junção das duas bases de dados.

\subsection{Construçáo das hipóteses}

Estudos prévios (Floriani, Fleury, 2012; Barcellos, 2010; Silva, Boaventura, 2011) indicam associação positiva entre grau de internacionalização e desempenho financeiro. A partir da observação da estrutura teórica, dois modelos econométricos foram desenvolvidos para os testes de hipóteses. A expectativa é de que, com a captação dos dados, com trabalho e análise através das opçôes de soluções de softwares, será possível identificar elementos que respondam às hipóteses.

Desta forma, estruturam-se quatro hipóteses neste trabalho, como apresentadas a seguir:

$\mathrm{H}_{1}$ : Quanto maior a Liquidez Geral maior é o grau de internacionalização; $\mathrm{H}_{2}$ : Quanto maior é a Margem Líquida maior é o grau de internacionalização; $\mathrm{H}_{3}$ : Quanto maior é a variação do Lucro por Ação maior é a variação do grau de internacionalização; e $\mathrm{H}_{4}$ : Quanto maior é a participação de capital de terceiros em relação aos ativos totais, maior é o grau de internacionalização. Dois modelos de regressão foram desenvolvidos para suportar as análises deste trabalho, com as seguintes características:

Modelo 1: procura analisar a relação entre as variaçôes IFDC e as variaçôes dos indicadores financeiros, Liquidez Geral, Margem Líquida, Lucro por Ação (LPA) e Estrutura de Capital.

$$
\begin{aligned}
\Delta I F D C & =\alpha+B_{1} \times \Delta L G+B_{2} \times \Delta M L+B_{3} \times \Delta L P A \\
& +B_{4} \times \Delta \mathrm{EC}+\varepsilon_{i t}
\end{aligned}
$$


Tabela 2. Siglas, Componentes e Fórmulla de Cálcullo - Modelo de Regressáo 1

\begin{tabular}{|l|l|l|}
\hline \multicolumn{1}{|c|}{ Sigla } & \multicolumn{1}{|c|}{ Componente } & \multicolumn{1}{c|}{ Fórmula de Cálculo } \\
\hline$\Delta I F D C$ & Variação do grau de internacionalização & $\Delta I F D C=\left(\frac{I F D C_{i t}}{I F D C_{i t-1}}\right)-1$ \\
\hline$\Delta M L$ & Variação na Margem Líquida & $M L=\frac{\text { Lucro Líquido }}{R O L} \times 100 ; \Delta M L=\left(\frac{M L_{i t}}{M L_{i t-1}}\right)-1$ \\
\hline$\Delta L P A$ & Variação do Lucro Por ação & $L P A=\frac{\text { Lucro Acionistas }(L A)}{A c ̧ \tilde{e s}(A)} \times 100 ; \Delta L P A=\left(\frac{L A_{i t}}{A_{i t-1}}\right)-1$ \\
\hline$\Delta E C$ & Estrutura de Capital & $E C=\frac{\text { Exigível Total }}{\text { Ativos Totais }} \times 100 ; \Delta M L\left(\frac{E C_{i t}}{E C_{i t-1}}\right)-1$ \\
\hline$\Delta L G$ & Variação da Liquidez Geral & $L G=\frac{A C+A N C}{P C+P N C} ; \Delta L G=\left(\frac{L G_{i t}}{L G_{i t-1}}\right)-1$ \\
\hline $\begin{array}{l}t \\
\varepsilon_{i t}=\text { Erro } \\
t \text { varia de 2011 a } 2015\end{array}$ &
\end{tabular}

Modelo 2: procura investigar a relação entre os indicadores financeiros e o nível de internacionalização dentro de um mesmo exercício financeiro. Neste modelo, as variáveis independentes não são variações entre períodos e, sim, o indicador existente no ano. Como o LPA não é um indicador padronizado, podendo modificar de acordo com o número de açóes das empresas, optou-se pela retirada desse componente do modelo.

$$
I F D C_{t}=\alpha+B_{1} \times L G_{t}+B_{2} \times M L_{t}+B_{3} \times \mathrm{EC}_{t}+\varepsilon_{i t}
$$

Onde: $I F D C_{t}$ é o Grau de Internacionalização no período $t$; $L G_{t}$ é a Liquidez Geral no período $t$; $M L_{t}$ é a Margem Líquida no período t; $E C_{t}$ é a Estrutura de Capital no período $t ; \varepsilon_{i t}=$ Erro; e $t$ varia de 2011 a 2015

Os dois modelos de regressão são modelos lineares nos parâmetros e nas variáveis e que de acordo com Gujarati (2005), permitem encontrar a variação absoluta na variável dependente para uma variação absoluta na variável independente.
Testes específicos foram aplicados para diagnosticar situaçóes que violam as premissas de modelos econométricos, como heterocedasticidade, linearidade, normalidade e multicolinearidade das variáveis independentes. Nestes modelos, foram aplicados o teste de $t$ Student como teste paramétrico, com nível de significância de 5\% para verificar a significância estatística de cada uma das variáveis.

\section{Análise dos resultados}

\subsection{Modelo 1}

Para a composição deste modelo de regressão, os cortes de variáveis consideradas outliers foram empreendidos como apresentado na seção de metodologia. Um total de 53 casos foram validados. Somente foram observadas correlaçóes significativas a um nível de 1\% entre: variaçáo da Liquidez Geral e a variação da Estrutura de Capital e; Variação da Margem Líquida e variação do Lucro por Ação. 
Tabela 3. Resultados da Regressáo - Modelo 1

\begin{tabular}{|c|c|c|c|c|c|}
\hline & \multicolumn{2}{|c|}{ Coeficientes não padronizados } & \multirow{2}{*}{$\mathbf{t}$} & \multirow{2}{*}{ Sig. } \\
\hline & & $B$ & Erro Padrão & & \\
\hline & (Constante) & $B_{0} 0,154$ & 0,040 & 3,828 & $0,00 \%$ \\
\hline & Variação da Liquidez Geral & $B_{1} 0,119$ & 0,291 & 0,410 & $68,4 \%$ \\
\hline & Variação da Margem Líquida & $B_{2} 0,207$ & 0,126 & 1,646 & $10,6 \%$ \\
\hline & Variação do Lucro por Ação & $B_{3}-0,216$ & 0,119 & $-1,817$ & $7,6 \%$ \\
\hline & Variação da Estrutura de Capital & $B_{4} 0,007$ & 0,308 & 0,022 & $98,3 \%$ \\
\hline $\mathrm{R}^{2}$ & $7,70 \%$ & & & & \\
\hline
\end{tabular}

Fonte: Dados da pesquisa.

O modelo de regressão apresentou qualidade do ajuste de $7,7 \%$, indicando que as variaçóes da Liquidez Geral, da Margem Líquida, do Lucro por Ação e da Estrutura de Capital conseguem explicar menos que $8 \%$ da variação da internacionalização da empresa. Dessa forma, cerca de $92 \%$ da variaçáo da atividade de internacionalização de uma empresa podem ser explicados por outras variáveis, como taxa de câmbio e variáveis associadas aos seus planejamentos.

Outra possibilidade diz respeito a relaçóes entre períodos superiores a um exercício. No caso deste trabalho, as variações foram obtidas entre um exercício e o outro imediatamente anterior. É possível que os efeitos da internacionalizaçáo em empresas brasileiras demorem mais que um ano para serem percebidos. Essa abordagem ganha ressonância no fato de que as variaçóes na estrutura de capital e liquidez geral não encontraram significância estatística no modelo.

Estabeleceu-se o limite de 5\% para os níveis de significância. $\mathrm{O}$ único coeficiente que atingiu valor inferior a esse patamar foi a Constante. O coeficiente de 0,154 indica que, quando as demais variáveis do modelo assumirem valor igual a zero, a variação da internacionalização, em média, teria aumentado em 15,4\%. Esse resultado é mais um indicador que denuncia que outros aspectos aderentes às organizaçóes podem estar associados às variaçóes de atividades de internacionalização das empresas brasileiras.

A variação do Lucro por Ação apresentou nível de significância inferior a $10 \%$. O coeficiente negativo de 0,216 indica que a variação de $1 \%$ no LPA é acompanhada de uma redução próxima de $2,16 \%$ no IFDC. Desta forma, é possível estabelecer a relação negativa entre o IFDC e o LPA de uma empresa.

As demais variáveis incluídas no modelo não apresentaram nível de confiança satisfatório. Não cabe então, estabelecer análises dos coeficientes das variaçóes da Margem Líquida, da Estrutura de Capital ou da Liquidez Geral. Como médias de atividades de internacionalização na faixa de $1 / 4$, é possível assumir que esse nível de atividade não tenha conexão com os indicadores financeiros gerais das empresas.

\subsection{Modelo 2}

A Tabela 4 traz os resultados do segundo modelo de regressão. A qualidade do ajuste foi melhor do que o modelo 1. Neste caso, as variáveis Margem Líquida, Liquidez Geral e Estrutura de Capital explicam quase $15 \%$ da internacionalização de uma empresa no 
Tabela 4. Resultados da Regressão - Modelo 2

\begin{tabular}{|l|l|c|c|c|c|}
\hline \multicolumn{2}{|c|}{} & \multicolumn{2}{|c|}{ Coeficientes não padronizados } & \multirow{2}{*}{ Sig. } \\
\cline { 2 - 5 } \multicolumn{2}{|c|}{} & B & Erro Padrão & T & \\
\hline \multirow{2}{*}{} & (Constante) & $B_{0} 0,239$ & 0,087 & 2,766 & $0,7 \%$ \\
\cline { 2 - 5 } & Liquidez Geral & $B_{1}-0,081$ & 0,045 & $-1,775$ & $7,9 \%$ \\
\cline { 2 - 5 } & Margem Líquida & $B_{2}-0,002$ & 0,001 & $-2,349$ & $2,1 \%$ \\
\cline { 2 - 6 } & Estrutura de Capital & $B_{3} 0,072$ & 0,001 & 0,747 & $45,7 \%$ \\
\hline$R^{2}$ & $17,5 \%$ & & & \\
\hline
\end{tabular}

Fonte: Dados da pesquisa.

mesmo ano. Os indicadores estatísticos de significância também foram melhores. A constante $(0,239)$ e a Margem Líquida $(0,021)$ ficaram com significância estatística inferior a 5\% como estabelecido nesta pesquisa. A constante de 0,239 indica que, mesmo para os casos em que Margem Líquida, Liquidez Geral e Estrutura de Capital for igual a zero, na média, o IFDC de uma organização será de 0,239.

A Margem Líquida está correlacionada negativamente com o IFDC. Essa condição mostra uma situação diversa da encontrada no Modelo 1. Naquele modelo, relaxando a significância para níveis próximos a 10\%, a variação na Margem Líquida foi positiva. No caso do Modelo 2, cuja investigaçáo ocorre dentro do mesmo exercício, essa relação foi negativa. É de se destacar que o coeficiente negativo de 0,002 mostra pouca variação. A elevação de uma unidade na Margem Líquida, em média, faz o IFDC reduzir em 0,002 .

Outra situação que denuncia as divergências encontradas entre os modelos diz respeito à Liquidez Geral. No Modelo da variação está bem distante estatisticamente a relação entre a variaçáo da Liquidez Geral e a variação do IFDC. No caso do segundo modelo, a relação existe a níveis inferiores a $10 \%$. Também se pode perceber uma relação negativa. $\mathrm{O}$ acréscimo de uma unidade no índice de Liquidez Geral reduz em 0,081 o IFDC, em média.

\section{Discussão dos resultados}

A proposta desta pesquisa reside na relação entre internacionalização e indicadores de performance financeira de curto prazo em empresas brasileiras de capital aberto. Não se pode afirmar que a Estrutura de Capital esteja relacionada ao IFDC. Essa informação requer maiores contribuições de pesquisa, no entanto, existe um forte indício de que o processo de internacionalização ocorra às margens de estruturas de capital voltadas para este fim. Esse encontro é aderente aos resultados de Silva e Boaventura (2011) que encontraram relação positiva, no entanto fraca, da internacionalização e indicadores financeiros de empresas brasileiras.

O modelo de variação apresentou qualidade inferior ao modelo que investiga no mesmo exercício. Essa condição pode reforçar o fato de que as variações entre exercícios, de curto prazo, são menos evidentes. Em outras palavras, os indicadores de performance são aderentes quando o olhar recai no mesmo exercício social. A partir da passagem de um ano, as relaçóes são mais fracas denunciando que os efeitos da internacionalização são menos evidentes nos anos subsequentes.

As empresas apresentam piora na Margem Líquida frente a um aumento no grau de internacionalização. Essa condição pode preocupar investidores, provedores 
de fundos e outros envolvidos. Aqui reforça a importância de ampliar a investigação para buscar identificar se, e quando, os efeitos da internacionalização podem ocorrer. A redução da margem líquida, quando incorrer maior atividade de internacionalização não acompanha os achados de Floriani e Fleury (2012), para pequenas e médias empresas, Barcellos (2010) e Silva e Boaventura (2011).

As divergências de encontros podem ter explicação na condiçóes e escopo de pesquisas empreendidos pelos demais investigadores. Floriani e Fleury (2012) pesquisaram pequenas e médias empresas. Silva e Boaventura (2011) e Barcellos (2010) apresentaram resultados de empresas brasileiras na década de 90 . Além desses aspectos, os três trabalhos não fizeram uso dos dados de internacionalização da Fundação Dom Cabral. Também neste fato pode residir os aspectos diferenciais entre os achados. Por fim, a seguir são expostas as hipóteses deste trabalho com os respectivos achados em ambos os modelos.

$\mathrm{H}_{1}$ : Quanto maior a Liquidez Geral maior é o grau de internacionalização.

Resultado do primeiro modelo econométrico: Hipótese não confirmada. Os resultados indicam que a variação da Liquidez Geral não explica a variação da internacionalização.

Resultado do segundo modelo econométrico: Hipótese náo confirmada. Os resultados indicam que a Liquidez Geral não tem poder de explicação do IFDC no mesmo exercício. A um nível de significância de $10 \%$ pode ser estabelecida a associação negativa entre o IFDC e a Liquidez Geral, também rejeitando a hipótese.

$\mathrm{H}_{2}$ : Quanto maior é a Margem Líquida maior é o grau de internacionalização.

Resultado do primeiro modelo econométrico: $\mathrm{Hi}$ pótese não confirmada. Os resultados indicam que a variação da Margem Líquida não explica a variação da internacionalização. É de se destacar que o resultado de significação ficou próximo de 10\%. Talvez uma amplitude maior na investigação, com prazos mais elásticos e novos anos compreendidos no escopo da pesquisa, possa caminhar para níveis que confirmem a hipótese.

Resultado do segundo modelo econométrico: Hipótese não confirmada. Foi encontrada significâncias estatísticas a níveis inferiores a $5 \%$ da relação negativa entre Margem Líquida e o IFDC. Destaca-se que o coeficiente encontrado tem valor substancialmente reduzido.

$\mathrm{H}_{3}$ : Quanto maior é a variação do Lucro por Ação maior é a variação do grau de internacionalização.

Resultado do primeiro modelo econométrico: Hipótese não confirmada. Os resultados indicam que a variaçáo do Lucro por Ação não explica a variação da internacionalização. Se houver um relaxamento do nível de significância para $10 \%$ pode ser confirmada essa hipótese.

Resultado do segundo modelo econométrico: Não aplicado no segundo modelo.

$\mathrm{H}_{4}$ : Quanto maior é a participação de capital de terceiros em relação aos ativos totais, maior é o grau de internacionalização.

Resultado do primeiro modelo econométrico: Hipótese não confirmada. A Estrutura de Capital foi o que menos mostrou relação com a internacionalização das empresas. Resultado do segundo modelo econométrico: Hipótese não confirmada. Os resultados indicam que a Estrutura de Capital não explica o IFDC. 


\section{Consideraçóes finais}

Esta pesquisa se pautou na busca de entender a relação entre indicadores de desempenho financeiro e grau de internacionalização de empresas brasileiras. Ressalta-se que a investigação proposta verificou a relação entre o grau de internacionalização e a performance financeira em um lapso temporal compreendido entre o exercício corrente e do ano imediatamente anterior. O primeiro modelo, com a inclusão das variações dos indicadores de performance financeira, buscava associar a variaçáo do grau de internacionalização às variações dos indicadores. O segundo modelo não foi desenvolvido fazendo uso de variaçóes, mas sim dos indicadores correspondentes para o próprio ano.

Não foi possível afirmar significativamente as relações entre grau de internacionalização e os indicadores de performance financeira, isso para ambos os modelos desenvolvidos. Essa resposta pode indicar algumas características associadas a empresas brasileiras. A internacionalização demora para compor efeitos nos indicadores financeiros de curto prazo, diferentemente dos resultados apresentados no referencial deste trabalho. Outra possibilidade é a de que os resultados encontrados são associados às organizaçóes que compuseram esta pesquisa, genuinamente composta por empresas que participaram da listagem de internacionalização divulgada pela Fundação Dom Cabral entre os anos de 2011 e 2015.

A qualidade do segundo modelo de regressão, próximo de $18 \%$, mostra que a inclusão de três variáveis independentes, no caso Liquidez Geral, Margem Líquida e Estrutura de Capital explicam quase de $1 / 5$ da internacionalização das empresas. Esse resultado pode ser considerado um bom sinalizador para pesquisas futuras, em que podem ser empreendidas algumas ações, como: utilização de outra métrica para o grau de internacionalização, não ficando restrita à metodologia da Fundação Dom Cabral; ampliação da amostra; expansão da comparaçáo dos resultados de empresas nacionais com de outros países e; dilatação do número de variáveis independentes nos modelos econométricos.

Os aspectos que envolvem a comparabilidade de empresas, ou mercados, por exemplo, podem ser mais desenvolvidos com pesquisas semelhantes a esta. $\mathrm{Na}$ visão de investidores, proprietários, funcionários, governo e outros, a maior demora para refletir nos indicadores financeiros as atividades de internacionalização podem conduzir àqueles que tomam decisóes, criando maiores exigências frente à futuras expansóes e mercados diferentes dos de origem.

Um componente qualitativo da internacionalização também se impóe como importante, ou seja, internacionalizar para onde? Mercados com distância psíquica semelhante ou divergente da brasileira modifica os indicadores de forma mais rápida? $\mathrm{O}$ indicador utilizado neste trabalho não contempla essa separação. Em outras palavras, duas empresas brasileiras podem ter indicadores de internacionalização semelhantes, mas um atua em uma país vizinho e a outra do outro lado do mundo. São questóes que os envolvidos podem requerer mais profundidade que este trabalho não contemplou.

Frente a isto cabe sugerir que investigaçóes contemplem empresas de outros países latino americanos, buscando entender se os indicadores financeiros de curto prazo são influenciados por maiores ou menores atividades de internacionalização. Uma abordagem comparativa entre os resultados de empresas brasileiras e de outros países. Além disso, fazer um recorte e investigar se existem modificaçóes relevantes nos indicadores para os casos de internacionalização das empresas na América do Sul, por exemplo. 
Por fim, mesmo com as restriçóes a seu desenvolvimento, pode-se aceitar que o trabalho obteve êxito em sua proposta, complementando as informaçóes referentes à performance financeira e ao grau de internacionalização de empresas brasileiras.

\section{Referências}

Barcellos, É. P. (2010). Internacionalização de empresas brasileiras: um estudo sobre a relação entre grau de internacionalização e desempenho financeiro. Dissertação - Sáo Paulo: Faculdade de Economia, Administração e Contabilidade (USP). https://doi. org/10.11606/D.12.2010.tde-08112010-161930

Carneiro, J. et al. (2016). How to measure export performance? Scholars' vs. practitioners' answers. Journal of Business Research, 69(2), 410-417. https://doi. org/10.1590/S1807-76922011000200002

Cieslik, J., Kaciak, E., Thongpapanl, N. (2015). Effect of export experience and market scope strategy on export performance: Evidence from Poland. International Business Review, 24(5) 772-780. https://doi. org/10.1016/j.ibusrev.2015.02.003

Dyment, J. J. (1987). Strategies and management controls for global corporations. Journal of Business Strategy, 7(4), 20-26, Spring. https://doi.org/10.1108/ eb039172

Floriani, D. E., Fleury, M. T. (2012). The Effect of the Degree of Internationalization on the International Competences and Financial Performance of Brazilian SMEs. Revista de Administração Contemporânea, 16(3), 438-458. https://doi.org/10.1590/S141565552012000300007

Foley, C. F., Manova, K. (2015). International Trade, Multinational Activity, and Corporate Finance. Annual Review of Economics, 7, 119-146. http://10.3386/ w20634 https://doi.org/10.3386/w20634

Gil, A. C. (1999). Métodos e técnicas de pesquisa social. 5 ed. São Paulo: Atlas.
Gujarati, N. (2005). Econometria aplicada. São Paulo: Pearson.

Hilal, A.; Hemais, C. A. (2003). O processo de internacionalização na ótica da escola nórdica: evidências empíricas em empresas brasileiras. Revista de Administração Contemporânea, 7(1), 109-124. https://doi. org/10.1590/S1415-65552003000100006

Marostica, J., Borgert, A., Souza, F. R. De, \& Petri, S. M. (2017). Comportamento dos custos e indicadores de endividamento e liquidez em empresas do setor de consumo listadas na BM\&FBovespa. Contabilidad y Negocios, 11(22), 6-21. https://doi.org/10.18800/ contabilidad.201602.001

Martinewski, A. L., Gomes, J. S. (2001). Management control in internationalized brazilian companies: a nine case comparative study. Adm. MADE (Universidade Estácio de Sá), Rio de Janeiro, I(2), 33-58.

Merchant, K. A. (1998). Modern management control systems: text \& cases. Upper Saddle River: Prentice-Hall.

Penman, S. H. (2013). Análise de demonstraçóes financeiras e security valuation. São Paulo: Elsevier.

Silva, P. P. M., Boaventura, J. M. G. (2011). Estratégia de internacionalização de firmas brasileiras e desempenho financeiro. Revista Ibero-Americana de Estratégia, 0421. https://doi.org/10.5585/riae.v10i3.1728

Teixeira, A. P. P., Flores, F. S. (2014). O modelo de internacionalização de Upsala sob a ótica da visão baseada em recursos (RBV). REAVI, 1-11. https://doi. org/10.5965/2316419003032014001

Venkatraman, N. e Ramanujam, V. (1986). Measrement of business performance in strategy research: a comparison of approaches. Academy of Management Review, 11(4), 801-814.

Fecha de recepción: 19 de setiembre de 2017 Fecha de aceptación: 16 de abril de 2018 Correspondencia: pinheirodesa@hotmail.com josirsgomes@gmail.com jadilsob@hotmail.com

Contabilidad y Negocios (13) 25, 2018 / ISSN 1992-1896 